\title{
EFEITO-PROFESSOR EM UM CURSO TÉCNICO EM SEGURANÇA PÚBLICA
}

LUIZ ALBERTO OLIVEIRA GONÇALVES JOSÉ FRANCISCO SOARES HÉLIO HIROSHI HAMADA

\section{RESUMO}

O objetivo deste artigo é apresentar os resultados de uma pesquisa sobre o efeito-professor no desempenho acadêmico de alunos do Curso Técnico em Segurança Pública da Polícia Militar de Minas Gerais, cujo alvo é formar soldados, ou seja, os profissionais que se encontram na base da atuação policial. Os dados foram organizados segundo as notas dos alunos nas diferentes disciplinas, por turma. Foram agrupadas as turmas com o mesmo professor para a mesma disciplina. Comparadas posteriormente, foi possivel evidenciar o efeito-professor analisando-se o coeficiente de variação da média e do desvio-padrão das notas finais das turmas para cada disciplina. Com base na identificação de disciplinas com maior coeficiente de variação, partiu-se para a análise de regressão linear múltipla, o que nos permitiu a verificação direta da existência do efeito-professor, sendo possivel saber qual deles teria feito diferença no desempenho de seus alunos. 


\section{RESUMEN}

El objetivo de este trabajo es presentar los resultados de una encuesta sobre el "efecto-profesor" en el rendimiento académico de los alumnos del Curso Técnico en Seguridad Pública de la Policía Militar de Minas Gerais cuya finalidad es formar soldados, es decir, los profesionales que se encuentran en la base de la actuación policial. Los datos para la organización fueron las notas de los alumnos en las diferentes asignaturas, por grupos reunidos con el mismo profesor para la misma asignatura. La comparación posterior permitió observar el efecto-profesor, analizando el coeficiente promedio de variación y el desvío estándar de las notas finales de los grupos en cada asignatura. Con base en la identificación de las asignaturas con mayor coeficiente de variación, se realizó el análisis de regresión lineal múltiple, lo que permitió la verificación directa de la existencia del efecto-profesor, siendo posible saber cuál habría producido una diferencia en el desempeño de sus estudiantes.

PALABRAS CLAVE: RENDIMIENTO ESCOLAR • SEGURIDAD

PÚBLICA • ENSEÑANZA PROFESIONAL • EVALUACIÓN DE LA APRENDIZAJE.

\section{ABSTRACT}

The aim of this paper is to present the results of a research on the "teacher-effect" on the academic performance of students at a technical course in Public Security from the Military Police of the state of Minas Gerais. The goal of the course is to train soldiers, i.e., the professionals who are at the basis of police action. The data were organized according to the scores students obtained in different disciplines, per class. Classes with the same teacher for the same discipline were grouped together. When later compared, it was possible to observe teacher-effect analyzing the coefficient of variation of the mean and the standard deviation of the final scores of the classes for each discipline. Based on the identification of disciplines with a higher coefficient of variation, we decided to analyze multiple linear regression, which allowed us to verify directly the existence of the teacher-effect, so that it was possible to know which of them would have made a difference in student performance.

KEYWORDS: STUDENT ACHIEVEMENT • PUBLIC SECURITY • TECHNICAL EDUCATION • LEARNING EVALUATION. 


\section{INTRODUÇÃO}

A formação de profissionais de Segurança Pública constitui um dos pilares para o desempenho eficaz de policiais no controle da criminalidade e da violência. Espera-se que o policial adquira, no período de formação, o conhecimento necessário para sua atuação. Entretanto, especialistas na área da Sociologia Criminal e da Segurança Pública têm alertado para as necessidades de melhoria da competência do "fazer" do policial, de forma a que este desempenhe de uma maneira mais eficiente, responsável e efetiva suas atividades. Destacam, entretanto, que essa melhoria está relacionada, entre outras coisas, aos modelos de formação que têm sido utilizados nas Academias de Polícia e nos Centros de Treinamento (PONCIONI, 2005; MUNIZ, 1999; KANT DE LIMA, 2003).

Com esses autores, tem-se aprendido que o estudo de fatores que interferem no processo de aprendizado dos policiais é um campo vasto e sua complexidade tem chamado a atenção para a necessidade da realização de pesquisas científicas envolvendo o tema da formação, com todas as implicações que ele impõe, que vão desde as condições físicas e materiais 
para a realização efetiva dos cursos até a gestão curricular e a competência do corpo docente (SAPORI, 2007).

$\mathrm{Na}$ busca por esclarecimentos dos fatores que interferem na atividade cognitiva dos agentes de segurança, a pesquisa que ora se apresenta buscou, no campo específico da Educação, teorias que envolvessem diretamente a educação profissional e, mais precisamente, aquelas que ajudam a correlacionar os diferentes fatores que podem estar impactando a formação desses profissionais. Foi nessa empreitada que se chegou aos estudos que envolvem o efeito-professor. Tais estudos reforçam a ideia de que o professor, enquanto ator significativo no processo de ensino, é o agente principal das decisões na sala de aula. Mesmo sem ter clareza do arbitrário que envolve suas escolhas, é ele quem concretiza a definição didático-pedagógica e aplica dentro de sala de aula um dado conteúdo (CUNHA, 2003).

Foi baseado nessas reflexões que se decidiu investigar o efeito-professor no ensino profissional de Segurança Pública. Ainda que na época, houvesse outros estudos com o objetivo de avaliar os resultados dos cursos de formação dos seus profissionais, a área da Segurança Pública, de uma forma geral, não contava com pesquisas que investigassem em que medida o professor afetava o processo cognitivo do aluno-policial. Assim, buscou-se realizar uma investigação voltada para a atividade exercida pelo professor no exercício de sua função dentro de uma instituição policial militar. Por ser um contexto completamente diferente daquele sobre o qual os especialistas da área da Educação construíram a teoria do efeito-professor, foram feitas adaptações conceituais e metodológicas que serão apresentadas e discutidas mais adiante, com o objetivo de preservar a validade e legitimidade do modelo.

A pesquisa teve como universo de investigação o Centro de Ensino Técnico pertencente à estrutura da Academia da Polícia Militar de Minas Gerais, onde se buscou estudar a eficácia de professores do Curso Técnico em Segurança Pública (CTPS). Cabe esclarecer que o referido curso tem a finalidade de formar soldados, ou seja, policiais militares que representam a base da Corporação. ${ }^{1}$ Trata-se da preparação do aprendiz de policial militar após o processo seletivo, momento em que recebe as noções menor graduação dentro dos básicas para seguir sua carreira profissional. 
2 JENCKS, Chistoper Inequality: a reassessment of the effect of family and schooling in America. New York: Basic Books, 1972

3 RUTTER, Michael et al. Fifteen thousand hours secondary schools and their effects on children Cambridge, Massachusetts: Harward University Press, 1979

4 SAMMONS, Pam. Schoo effectiveness: coming of age in the twenty-first century. Lisse: Sweets \& Zeitlinger, 1999

\section{A CONSTRUÇÃO DO MODELO DE INVESTIGAÇÃO}

Pelo fato de o núcleo central do objeto da pesquisa ser o efeito-professor no desempenho dos alunos, partiu-se da premissa de que o bom desempenho dos estudantes não se reduz à relação entre um professor e seus respectivos alunos. Para atingi-lo, faz-se necessária a presença de outros fatores que, em certos contextos, podem favorecer (ou não) as aquisições dos alunos e, consequentemente, o seu próprio desempenho.

Entre os estudiosos das teorias do efeito-professor e do efeito-escola estão pesquisadores europeus e norte-americanos (COLEMAN et al., 2008; JENCKS, 1972; ${ }^{2}$ RUTTER et al., 1979; ${ }^{3}$ SAMMONS, 1999, ${ }^{4}$ apud BROOKE; SOARES, 2008, e outros). No cenário nacional, destaca-se em especial o estudo de Alves (2006), onde a autora defende uma ideia sobre a qual muito já se escreveu nas pesquisas educacionais, a saber, que alguns professores, dentro de certas condições, têm feito diferença no desempenho de seus alunos. Ainda sobre esse tema, Brooke e Soares (2008) organizaram, no Brasil, um estudo que difunde textos clássicos sobre essa temática, que, além de tratarem da sua origem e de sua trajetória no campo das medidas educacionais, apresentam inúmeros exemplos de sua aplicação. Foi daí que se extraíram as ferramentas que contribuíram para a análise e a comparação dos dados do presente artigo.

Seguimos as pistas oferecidas por essas obras que, pautadas em uma ideia difundida pelas Ciências Sociais, defendem a tese de que quase todo material coletado em uma pesquisa empírica possui um padrão hierárquico ou contextual inequívoco. Por isso, sugere-se que se construa um modelo de análise que considere os diferentes níveis aos quais esses dados estão associados. Ou seja, ao analisá-los, é preciso que os pesquisadores estabeleçam as conexões que os dados coletados mantêm com os diferentes níveis da estrutura social à qual se referem. Por exemplo, ao se coletarem dados sobre os alunos, é preciso considerar, na análise desses dados, que esses alunos estão agrupados em classes seriadas, e que estão em diferentes escolas que, por sua vez, estão em diferentes regiões geográficas de um bairro e de uma cidade. E tudo isso está hierarquicamente relacionado. O mesmo ocorre quando se coletam dados referentes aos professores. Eles estão associados a famílias que vivem em locais distintos em termos sociais e demográficos.Nas escolas, esses professores 
estão associados hierarquicamente a supervisores pedagógicos distintos, além de poderem estar lecionando em escolas diferentes em termos socioeconômicos.

Quanto aos procedimentos analíticos, o modelo multinível foi o método adotado para medir as influências do efeito-professor no Curso Técnico em Segurança Pública. A sua utilização tem a vantagem de propiciar um tratamento dos dados de forma a que estes não se incorporem naturalmente na estrutura da regressão logística e podem ser agrupados em níveis hierárquicos, tais como: alunos em turmas, turmas em escolas e escolas em municípios (BARBOSA; FERNANDES, 2001, p. 4). Assim, pôde-se modelar o relacionamento entre diversas variáveis preditivas com uma variável resposta. Dito de outra forma, introduziram-se variáveis como sexo, idade e nível socioeconômico, para ver, no desempenho final dos alunos em determinada disciplina, qual é a relação e o grau de influência de cada uma dessas variáveis por níveis de agrupamento.

Neste estudo, as notas finais dos alunos com relação a cada disciplina do curso formaram a base para a organização dos dados. Em termos mais técnicos, essas notas se constituíram no que se chama de variável dependente. Em seguida, selecionaram-se as variáveis para compor o modelo multinível, a saber: sexo dos alunos, nota de classificação que cada aluno obteve no concurso de entrada na Polícia Militar, a situação do aluno no curso (matrícula normal ou sob liminar judicial), turma e professor de cada disciplina. Uma vez organizados os dados, foram agrupadas as turmas que tiveram aula com determinado professor para que, em uma comparação entre as turmas, fosse evidenciado o efeito-professor. Essa aferição foi inicialmente realizada pela análise do coeficiente de variação da média e do desvio-padrão das notas finais das turmas para cada disciplina. Com base na identificação de disciplinas com maior coeficiente de variação, partiu-se para a análise de regressão linear múltipla, o que nos permitiu a verificação direta da existência desse efeito, sendo possível saber qual professor se saiu melhor em cada disciplina.

Em que pese o sistema de educação profissional da Polícia Militar de Minas Gerais estar estruturado em setores descentralizados na capital e no interior do estado, para a efetivação da coleta de dados, este estudo concentrou-se no corpo docente ${ }^{5}$ e discente do Curso Técnico em Segurança
5 As 35 (trinta e cinco) disciplinas do CTSP estão divididas nas seguintes áreas: missão policial, técnicas de defesa pública, polícia ostensiva, eficácia pessoal, linguagem e informação, cultura jurídica. Para cada disciplina são designados em torno de dez professores. 
Pública/2006, que compreendeu 958 alunos do sexo masculino e 250 do sexo feminino. O estudo se realizou no Centro de Ensino Técnico da Academia de Polícia Militar em Belo Horizonte/MG, iniciado no mês de agosto de 2006 e com término no mês de junho de 2007. Dito isso, apresentam-se, a seguir, os dados que foram analisados.

\section{ANÁLISE DAS EVIDÊNCIAS DO EFEITO-PROFESSOR CONSIDERAÇÕES ACERCA DA ANÁLISE DE DADOS}

Para realizar a análise dos resultados, é conveniente ressaltar que, apesar de ter sido orientado pelas teorias do efeito-professor, cujas pesquisas originais foram realizadas em sistemas educacionais regulares, algumas variáveis que seriam consideradas naquelas instituições exerciam pouca influência em nosso estudo, em função das particularidades da educação profissional da Polícia Militar. Uma delas que merece ser citada é a própria delimitação do universo em um único centro de ensino, excluindo-se, nesse aspecto, a comparação que é feita nos estudos de efeito-escola, que abrange o desempenho de alunos de instituições diferentes, estando incluído o professor como uma das variáveis.

Em geral, nos estudos sobre o efeito-escola, os pesquisadores procedem a comparações entre estabelecimentos de ensino diferentes, como foi o caso do clássico estudo de Coleman e colegas (1998 apud BROOKE; SOARES, 2008, p. 26-32), para auferir a "diferença" que uma escola faria em relação à outra que agregou alunos de um mesmo extrato social. Por isso, não se buscou analisar o efeito-escola, uma vez que o nosso estudo se concentrou em um único centro de ensino, o que permitia a comparação intraestabelecimento. Mas, em compensação, como assinala Bressoux (2003), em um único estabelecimento de ensino é possível medir o efeito-professor comparando-se o desempenho de docentes em uma mesma turma e desses mesmos docentes em outras turmas. Mas, para tanto, é necessário ter alguns cuidados metodológicos. O primeiro deles é garantir a homogeneidade das turmas nas quais esses professores atuam. Homogeneizar não significa aqui que haverá alunos idênticos em cada turma, até porque isso seria impossível. Em 
termos científicos, significa um esforço do pesquisador para controlar o máximo possível de variáveis que, se não controladas, poderiam afetar o resultado do estudo. No nosso caso específico, uma variável não controlada poderia dificultar o "isolamento" do efeito-professor, ou seja, poderia competir com a variável efeito-professor na explicação do bom ou mau desempenho do aluno.

Em nossa pesquisa, alguns fatores propiciaram a homogeneização dos grupos nos quais se buscou medir o efeito-professor. Em primeiro lugar, destaca-se o fator "seleção". A seletividade nos sistemas educacionais é um fenômeno já amplamente estudado, desde a década de 1980 (MELLO, 1983; ROSEMBERG, 1984). A teoria de seletividade escolar indica que as escolas tendem a congregar crianças e adolescentes de um dado extrato social. Em outros termos, segundo essa teoria, alguns fatores estão embutidos no efeito-seleção. Para esclarecer o que diz a teoria, Alves (2006) explica que, no Brasil, as escolas são fortemente segmentadas por filtros socioeconômicos e culturais, que produzem um efeito de seleção em toda a rede escolar, caso das escolas públicas federais que fazem seleção (Militar, Coltec e Cefet) ${ }^{6}$ e das escolas particulares. Isso não significa que eles selecionam os melhores alunos de um universo mais amplo, mas que selecionam os melhores de um dado extrato social. Soares e Andrade (2006, p. 119) acrescentam que "a forma de seleção dos alunos das escolas federais, além de operar no âmbito cognitivo, influencia o seu nível socioeconômico, maior do que das outras escolas públicas". Sendo assim, a observância do efeito-seleção tende a controlar fatores socioeconômicos e culturais de um dado segmento da sociedade.

Esse controle é importante porque contribui para isolar fatores que poderiam impactar o desempenho dos alunos, impedindo-os de interferir no efeito-professor. Como dito anteriormente, importantes estudos já mostraram que fatores relacionados, por exemplo, ao capital cultural dos alunos têm o efeito preponderante em seu desempenho escolar. Assim, o efeito-seleção implica que esses fatores já estão embutidos na escolha e que todos os alunos que passaram pelo processo seletivo derivam de um mesmo segmento social e são muito semelhantes no que tange ao quadro social de origem. E, por terem sido selecionados para um número reduzido de vagas,
6 A autora refere-se a instituições de ensino de Minas Gerais: Colégio Militar, Colégio Técnico da Universidade Federal de Minas Gerais (UFMG) e Centro Federal de Educação Tecnológica de Minas Gerais. 
acredita-se que ali estejam os melhores do seu extrato social. De certa forma, esse foi o raciocínio que orientou o procedimento de escolha dos grupos observados em nossa pesquisa.

A seleção, no caso do Curso Técnico de Segurança Pública, é feita por concurso público, o que foi um aspecto importante para a presente pesquisa, porque, por meio dela, foi possível fazer o controle na análise a respeito dos fatores associados diretamente ao desempenho do aluno. Portanto, o acesso ao Curso Técnico de Segurança Pública é seletivo e, assim, pode-se considerar que existe o efeito-seleção. Para se ter uma ideia dessa seletividade, denota-se que a disputa para o acesso à carreira inicial de policial militar é maior do que o acesso aos cursos mais concorridos da Universidade Federal de Minas Gerais. Segundo o Centro de Recrutamento e Seleção da Polícia Militar de Minas Gerais, em 2005, a relação era de 35 candidatos por vaga, número superior ao curso mais concorrido da UFMG no vestibular de 2006, que foi o de Medicina $(29,14$ candidatos por vaga) (MINAS GERAIS, 2008, p. 39-40).

Passa-se agora a explicar os critérios para a distribuição dos alunos nas turmas. Após a fase de seleção feita por concurso público, o candidato selecionado passa à condição de aluno do Curso Técnico em Segurança Pública. Especificamente para o ano de 2006, os alunos foram distribuídos nas turmas de acordo com a classificação no concurso, ou seja, o $1^{\circ}$ colocado na turma 1 , o $2^{\circ}$ colocado na turma 2 , o $3^{\circ}$ colocado na turma 3, e assim progressivamente até turma 35, retornando-se à turma 01 para o próximo aluno. Procurou-se sempre evitar que nas turmas houvesse apenas um discente do sexo feminino. Uma vez distribuídos por turma, os discentes foram classificados por ordem alfabética. Essa distribuição produziu, como se pôde observar posteriormente, uma homogeneidade nas turmas, suscitada pelo viés seletivo do próprio concurso público, estando o efeito-seleção presente na composição das turmas.

O segundo aspecto a ser considerado é com relação à avaliação dos alunos nas diversas disciplinas durante o curso. Uma vez ingressado e cursando as diferentes matérias, o aluno, para ser aprovado, deve atingir uma pontuação mínima de 6,0 pontos em cada disciplina. As provas aplicadas 
aos discentes são padronizadas e passam por revisões de forma e conteúdo por parte do setor técnico de ensino do Centro de Ensino Técnico. A mesma prova é realizada no mesmo dia e horário. Esse procedimento permite que se reduzam possíveis vieses de "contaminação" (circular informações da prova antes de sua realização) que poderiam ocorrer caso fossem aplicadas em dias diferentes para turmas diferentes.

A organização pedagógica é outro fator de influência para a compreensão das atividades de educação realizadas no Centro de Ensino Técnico. Destacam-se, nesse ponto, a padronização dos planos de curso e os programas de disciplina que orientam os docentes na administração do conteúdo a ser ministrado. É oportuno destacar que, para cada disciplina, há um coordenador que é designado pelo Centro de Ensino Técnico, escolhido dentre os professores da matéria. O coordenador da disciplina é responsável não só por reunir os demais professores, antecipando o início das aulas, como também por definir procedimentos padronizados e adequar os planos de curso e programas de disciplina.

Como último aspecto a ser considerado para o controle dos fatores, tem-se o fato de que o Curso Técnico em Segurança Pública é realizado em um único centro e os recursos físicos e pedagógicos disponibilizados para os alunos e professores em suas diversas atividades buscam atender a todas as turmas de forma equitativa, na medida de sua disponibilidade. Alguns recursos são disponibilizados de forma mais ampla, tais como a biblioteca e seu acervo e a internet. Outros recursos, como audiovisuais e multimídia, são mais limitados e dependem de agendamento, o que pode restringir a atuação dos professores que deles fazem uso. Em compensação, há em todas as salas retroprojetor e quadro branco. Em linhas gerais, e segundo critérios técnicos educacionais relativos às condições necessárias para um funcionamento adequado e eficaz do ambiente de aprendizagem, o Centro conta com insumos escolares, materiais que, teoricamente, atendem às exigências técnico-pedagógicas do curso. 


\section{IDENTIFICANDO O EFEITO-PROFESSOR}

\section{NO CURSO TÉCNICO EM SEGURANÇA PÚBLICA}

Uma vez esclarecidos alguns fatores relativos aos insumos escolares, avança-se para a descrição dos procedimentos adotados para identificar o efeito-professor. Os dados considerados para a observação foram as notas finais que cada aluno recebeu em cada disciplina do curso. O objetivo inicial foi conhecer, no conjunto das turmas, qual teria sido a média aritmética do total das notas para cada professor e a variabilidade dos valores individuais em torno dessa média, ou seja, conhecer o quanto cada nota individual se aproximava ou se distanciava da média final da turma em cada disciplina.

Como dito anteriormente, para ser aprovado nas disciplinas do curso, o aluno precisava ter notas acima de 6,0 pontos, porém, a variação das notas poderia ir de 0 a 10 , pois, nos dados coletados, não apareciam as notas das avaliações especiais dos alunos que não tinham conseguido a nota mínima. Concentrando-se, assim, a observação no conjunto de notas, pretendia-se conhecer os professores que poderiam ter tido algum efeito sobre a turma a ponto de propiciar um bom rendimento dos alunos, permitindo, no conjunto, não só uma média alta para a turma, como também um rendimento para cada aluno individualmente, de forma a que ele conseguisse uma nota próxima dessa média. Ou seja, para ter algum efeito sobre a turma, o professor precisaria conseguir que os alunos obtivessem notas maiores, de modo a reduzir a vulnerabilidade no interior da turma, inibindo dispersões que, em geral, ocorrem em relação à média.

Com esse tipo de preocupação, o estudo do efeito-professor ajuda, de certa forma, a corrigir um tipo de visão enganosa que se tem, por vezes, acerca do desempenho dos alunos, sobretudo em situações como a que nos dispusemos a estudar, na qual as diferentes turmas do curso tendem a ser representadas como se fossem homogêneas, produzindo resultados de desempenho, muito próximos entre si, em termos de média aritmética. Isso pode levar a um julgamento enganoso de que existe pouca variabilidade tanto no interior de cada turma, quanto das turmas entre si, o que não é correto, como mostraremos mais adiante.

Em se tratando de um enfoque sobre questões de impacto no desempenho cognitivo, autores têm mostrado que há uma 
série de fatores que produzem variabilidades e discrepâncias na distribuição dos valores traduzidos em notas. E há, também, procedimentos técnicos que, na realidade, encobrem as dispersões, dando-se uma falsa imagem de um todo homogêneo e de alto rendimento (ALVES, 2006; ALVES; SOARES, 2007; SOARES; COLLARES, 2006).

A esse respeito, parece importante evocar, neste estudo, o fato de que uma parte significativa do tratamento dado às avaliações na área da educação tem se contentado com resultados que apenas comparam as médias relativas ao conjunto de notas dos alunos nessa ou naquela disciplina, alardeando os altos escores, como se estes revelassem por si sós todo o universo de aprendizado, independentemente de sua variabilidade.

Estudiosos preocupados com a variação, ou, como eles próprios classificam, com as dispersões existentes em um conjunto de dados observados, têm insistido nos cuidados que precisam ser tomados em uma análise rigorosa, para que essas dispersões não passem despercebidas (BASTOS; DUQUIA, 2007. p. 40-44). As consequências dessa não percepção podem ser inúmeras (ALVES; SOARES, 2007). Segundo Bastos e Duquia (2007), chega-se ao reconhecimento da existência ou não dessa dispersão comparando-se as avaliações de duas ou mais disciplinas, ministradas por professores diferentes. Esse tratamento de dados foi feito, em linhas gerais, no presente trabalho. Por exemplo, na comparação entre a disciplina Ética Profissional e Cidadania e Legislação Jurídica Especial, obtiveram-se os seguintes resultados: 
TABELA 1 - Comparação de notas nas disciplinas de Ética Profissional e Cidadania e Legislação Jurídica Especial no CTSP/2006

\begin{tabular}{|c|c|c|}
\hline \multirow{2}{*}{$\begin{array}{l}\text { ALUNO DA TURMA } 05 \\
\text { DO CTSP/2006 }\end{array}$} & \multicolumn{2}{|c|}{ DISCIPLINA } \\
\hline & ÉTICA & LEGISLAÇÃO JURÍDICA \\
\hline 1 & 9,00 & 9,15 \\
\hline 2 & 8,50 & 7,65 \\
\hline 3 & 9,30 & 9,35 \\
\hline 4 & 7,80 & 9,15 \\
\hline 5 & 7,80 & 6,65 \\
\hline 6 & 8,30 & 8,75 \\
\hline 7 & 9,00 & 8,15 \\
\hline 8 & 9,00 & 8,70 \\
\hline 9 & 7,60 & 9,10 \\
\hline 10 & 8,90 & 7,30 \\
\hline 11 & 9,20 & 9,40 \\
\hline 12 & 9,10 & 9,60 \\
\hline 13 & 8,90 & 9,00 \\
\hline 14 & 7,60 & 8,45 \\
\hline 15 & 8,80 & 8,75 \\
\hline 16 & 8,80 & 9,45 \\
\hline 17 & 9,10 & 8,85 \\
\hline 18 & 7,30 & 8,60 \\
\hline 19 & 7,80 & 7,95 \\
\hline 20 & 8,90 & 8,30 \\
\hline 21 & 9,50 & 8,40 \\
\hline 22 & 7,00 & 8,30 \\
\hline 23 & 8,00 & 8,35 \\
\hline 24 & 8,70 & 7,55 \\
\hline 25 & 8,50 & 8,30 \\
\hline 26 & 7,00 & 9,20 \\
\hline 27 & 9,30 & 9,20 \\
\hline 28 & 6,90 & 8,05 \\
\hline Média da Turma & 8,41 & 8,56 \\
\hline
\end{tabular}

Fonte: Academia de Polícia Militar (HAMADA, 2008).

Como se pode perceber na Tabela 1 , as médias comparadas são muito próximas, $(8,41$ e 8,56$)$, mas a distribuição das notas de onde elas derivam são diferentes entre si, apresentando uma variabilidade que precisa ser medida.

Visto que uma mesma disciplina é dada por professores diferentes, incluiu-se também na análise a comparação das médias que as turmas de cada um desses professores alcançaram. Por exemplo, comparando-se as notas de turmas diferentes de uma mesma disciplina ministrada por professores 
diferentes, chegou-se aos seguintes resultados na disciplina de Ética Profissional e Cidadania:

TABELA 2 - Comparação de notas na disciplina de Ética Profissional e Cidadania no CTSP/2006

\begin{tabular}{|c|c|c|c|}
\hline \multicolumn{2}{|c|}{ TURMA 2} & \multicolumn{2}{|c|}{ TURMA 7} \\
\hline ALUNO & NOTA & ALUNO & NOTA \\
\hline 1 & 6,05 & 1 & 9,80 \\
\hline 2 & 7,19 & 2 & 8,80 \\
\hline 3 & 6,25 & 3 & 9,30 \\
\hline 4 & 6,69 & 4 & 8,40 \\
\hline 5 & 7,24 & 5 & 9,50 \\
\hline 6 & 6,40 & 6 & 8,60 \\
\hline 7 & 6,05 & 7 & 8,80 \\
\hline 8 & 7,43 & 8 & 8,30 \\
\hline 9 & 8,10 & 9 & 7,90 \\
\hline 10 & 6,00 & 10 & 9,10 \\
\hline 11 & 6,04 & 11 & 9,10 \\
\hline 12 & 6,76 & 12 & 9,80 \\
\hline 13 & 6,42 & 13 & 8,30 \\
\hline 14 & 7,30 & 14 & 9,30 \\
\hline 15 & 6,00 & 15 & 9,50 \\
\hline 16 & 6,50 & 16 & 8,40 \\
\hline 17 & 6,25 & 17 & 9,30 \\
\hline 18 & 6,95 & 18 & 9,10 \\
\hline 19 & 7,70 & 19 & 8,60 \\
\hline 20 & 6,50 & 20 & 9,20 \\
\hline 21 & 6,05 & 21 & 9,30 \\
\hline 22 & 7,94 & 22 & 8,90 \\
\hline 23 & 6,00 & 23 & 9,30 \\
\hline 24 & 6,30 & 24 & 9,20 \\
\hline 25 & 6,45 & 25 & 9,10 \\
\hline 26 & 6,54 & 26 & 8,80 \\
\hline 27 & 6,00 & 27 & 9,10 \\
\hline 28 & 6,12 & 28 & 8,55 \\
\hline 29 & 7,30 & 29 & 9,10 \\
\hline 30 & 7,60 & 30 & 8,30 \\
\hline 31 & 6,85 & & \\
\hline Média da Turma & 6,68 & Média da Turma & 8,96 \\
\hline
\end{tabular}

Fonte: Academia de Polícia Militar (HAMADA, 2008).

A tabela acima permite visualizar como, em uma mesma disciplina, pode haver variação na distribuição de notas. Tendo sido ministrada por professores diferentes, é possível buscar medir se houve influência desses docentes nos resultados, 
controlando-se, é claro, outras variáveis que poderiam estar conjuntamente interferindo.

Com esses dois exemplos, pode-se estimar a importância de se conhecer a média aritmética das turmas (medida de tendência central), uma vez que ela permite que se visualize onde a maior parte dos indivíduos se encontra, ou seja, pode ser interpretada, como dizem Soares e Siqueira (1999, p. 93), "como o centro de gravidade, isto é, o ponto de equilíbrio das discrepâncias positivas e negativas”. Mas ela permite também saber como esses dados (observações) estão distribuídos na população estudada.

Como a média aritmética considera "todos os valores da amostra" que, neste caso, são todas as notas dos alunos, isso faz com que "os valores muito grandes ou muito pequenos, comparados aos demais valores da amostra, causem grandes variações na média” (SOARES; SIQUEIRA, 1999, p. 54). A questão é saber se esses valores estão bastante próximos ou variam muito. Em todo caso, neste estudo, foram considerados os valores que variam as notas de 0 a 10.

Essa variabilidade, como indicam Bastos e Duquia (2007), pode ser visualizada graficamente e mensurada estatisticamente. E, por isso, precisa ser conhecida, pois "quase nunca uma única medida de tendência central é suficiente para descrever, de modo satisfatório, um conjunto de dados" (SOARES; SIQUEIRA, 1999, p. 55).

Na sequência, Soares e Siqueira (1999) destacam que "não basta saber o valor em torno do qual os dados se concentram. É preciso conhecer também o grau de agregação, ou seja, definir e usar medidas de dispersão de dados”. É por meio dessas medidas que se pode conhecer, na distribuição dos valores, se as notas recebidas pelos alunos em cada disciplina estão próximas entre si ou dispersas. Que medidas são essas?

Com base nas duas obras consultadas sobre o assunto, pode-se argumentar que a variabilidade (ou dispersão) das notas dos alunos do CTSP tem possibilidade de ser quantificada por intermédio da amplitude da variação, da variância, do desvio-padrão, do coeficiente de variação, entre outros (BASTOS; DUQUIA, 2007; SOARES; SIQUEIRA, 1999). Cada um desses procedimentos tem vantagens e desvantagens de acordo com o conjunto de dados disponíveis e com a possibilidade de comparação entre eles. 
Por exemplo, o desvio-padrão destaca-se por seu amplo uso na literatura científica (SOARES; SIQUEIRA, 1999, p. 55). Suas vantagens são muitas. Uma delas reside no fato de que, diferentemente da variância, ele conserva a unidade de mensuração original das observações, enquanto aquela (a variância) a eleva ao quadrado para calcular a dispersão. Outra vantagem do uso do desvio-padrão é que, conhecido o seu valor e o da média aritmética de uma dada distribuição, é possível saber se esta distribuição tende para uma forma simétrica, dita normal, ou assimétrica. Nessa segunda forma, o desvio-padrão será mais que a metade da média aritmética.

Considerar, entretanto, se o valor do desvio-padrão é grande ou pequeno depende, de acordo com Soares e Siqueira (1999, p. 58), "da ordem de grandeza da variável". No dizer desses autores, "um desvio-padrão de 10", por exemplo, "pode ser insignificante se a observação típica for 10.000 ”. Mas será muito significativa "para um conjunto de dados cuja observação típica é 100”. Por isso, os mesmos autores sugerem ser "conveniente exprimir a dispersão em termos relativos", expressando a "variabilidade dos dados tirando a influência da ordem de grandeza da variável”.

Ainda segundo Soares e Siqueira (1999, p. 58), a medida utilizada para obter esse índice relativo da dispersão é o coeficiente de variação (CV). Este é "adimensional, isto é, um número puro", usualmente "expresso em porcentagem". A utilidade do coeficiente de variação é "fornecer uma medida da homogeneidade do conjunto de dados". Se não houver variabilidade entre os dados, quando o (desvio padrão) $S=0$, é porque todos os valores da amostra são iguais.

A interpretação dos resultados do coeficiente de variação obedece à seguinte orientação: quanto menor for o coeficiente de variação, mais homogêneo é o conjunto de dados. Para sua análise, os autores acima citados propõem a seguinte classificação: será considerado de baixa homogeneidade, quando os valores forem inferiores a 0,10 ; será de média homogeneidade quando variar de 0,10 a 0,20 , alta, quando oscilar de 0,20 a 0,30 e muito alta quando for superior a 0,30 (SOARES; SIQUEIRA, 1999, p. 58).

O coeficiente de variação que se refere, no dizer de Bastos e Duquia (2007), à divisão entre o desvio-padrão e a média de uma distribuição, tem uma grande vantagem em relação 
às outras medidas de dispersão porque, por meio dele, pode-se comparar a dispersão entre duas variáveis, "mesmo que estas tenham sido mensuradas em escalas de medidas diferentes e que possuam médias diferentes".

Os dados que compõem o presente estudo se caracterizavam em parte pela maneira como foi descrita acima. Diz-se em parte porque as notas dos alunos, é claro, não foram medidas com escalas diferentes, pois as unidades para mensurá-las foram padronizadas pela equipe técnica do Centro e controladas pelos coordenadores de disciplina. Entretanto, as médias aritméticas em cada disciplina variam quase completamente. Diante dessa especificidade, entendeu-se que o coeficiente de variação seria o instrumento mais adequado para medir as dispersões de dados do universo que se estava estudando. Assim, o coeficiente de variação foi calculado para cada disciplina do CTSP, cujo resultado é apresentado na Tabela 3.

Seguindo-se a lógica do cálculo do coeficiente de variação, reza o modelo que, quanto menor o seu valor, mais homogêneo é o conjunto de dados, isto é, menos dispersão existe entre as notas de cada aluno nas respectivas disciplinas em relação à média aritmética total de cada turma e vice-versa, e quanto maior o seu valor, maior a dispersão. Assim, na tabela acima, pode-se observar que, das 35 disciplinas ministradas no CTSP, nenhuma obteve coeficiente considerado alto (entre 0,20 e 0,30 ) e nem muito alto (superior a 0,30 ). No conjunto, 14 disciplinas apresentam coeficiente de variação considerado baixo (inferior a 0,10 ), o que significa que é baixa a variabilidade das notas em torno da média. $E$ ainda, as outras 19 disciplinas tiveram um coeficiente de variação considerado "médio" (de 0,10 a 0,20 ), o que indica que houve alguma variabilidade em torno da mesma.

Embora não se tenha apresentado coeficiente de variação que se possa classificar como alto ou muito alto, decidiu-se, assim mesmo, verificar os fatores que poderiam explicar a média diferença apresentada pelas disciplinas que atingiram os maiores valores dentro do quadro estudado. Dessa forma, para efeito de apresentação, selecionaram-se três das sete disciplinas com valores acima de 0,12, para serem analisadas no presente estudo, a saber: Ética Profissional e Cidadania $(0,12)$, Análise Criminal $(0,12)$ e Informática Aplicada $(0,15)$. 
TABELA 3 - Coeficiente de variação das disciplinas do CTSP/2006

\begin{tabular}{|c|c|c|}
\hline DISCIPLINA & $\begin{array}{l}\text { NÚMERO DE } \\
\text { PROFESSORES }\end{array}$ & $\begin{array}{l}\text { COEFICIENTE DE } \\
\text { VARIAÇÃO }\end{array}$ \\
\hline Criminalística & 10 & 0,06 \\
\hline Policiamento Ambiental & 10 & 0,06 \\
\hline Técnica Policial & 15 & 0,07 \\
\hline $\begin{array}{l}\text { Comunicações } \\
\text { Operacionais PM }\end{array}$ & 11 & 0,07 \\
\hline $\begin{array}{l}\text { Comunicação } \\
\text { Organizacional }\end{array}$ & 13 & 0,08 \\
\hline $\begin{array}{l}\text { Legislação Jurídica } \\
\text { Especial }\end{array}$ & 11 & 0,08 \\
\hline Ordem Unida & 17 & 0,08 \\
\hline Policiamento de Trânsito & 12 & 0,08 \\
\hline $\begin{array}{l}\text { Policiamento Ostensivo } \\
\text { Geral }\end{array}$ & 11 & 0,09 \\
\hline Direitos Humanos & 13 & 0,09 \\
\hline Gerenciamento de Crises & 11 & 0,09 \\
\hline Direito Civil & 9 & 0,09 \\
\hline Sistemas Policiais & 10 & 0,09 \\
\hline Educação Física & 14 & 0,09 \\
\hline Direito Penal & 11 & 0,09 \\
\hline Defesa Pessoal Policial & 11 & 0,09 \\
\hline Legislação Institucional & 13 & 0,10 \\
\hline Armamento e Munições & 18 & 0,10 \\
\hline Drogas e Violência & 9 & 0,10 \\
\hline Direito Administrativo & 11 & 0,10 \\
\hline Atividades de Inteligência & 13 & 0,10 \\
\hline História da PMMG & 9 & 0,10 \\
\hline Direito Constitucional & 10 & 0,11 \\
\hline Direito Processual Penal & 11 & 0,11 \\
\hline $\begin{array}{l}\text { Sociologia do Crime } \\
\text { e da Violência }\end{array}$ & 11 & 0,11 \\
\hline Tiro Policial & 17 & 0,11 \\
\hline Policiamento de Guardas & 10 & 0,11 \\
\hline Língua Portuguesa & 8 & 0,11 \\
\hline $\begin{array}{l}\text { Ética Profissional e } \\
\text { Cidadania }\end{array}$ & 13 & 0,12 \\
\hline Análise Criminal & 13 & 0,12 \\
\hline Redação de documentos & 6 & 0,12 \\
\hline Chefia e Liderança & 18 & 0,12 \\
\hline Polícia Comunitária & 14 & 0,12 \\
\hline Pronto-socorrismo & 13 & 0,13 \\
\hline Informática Aplicada & 10 & 0,15 \\
\hline
\end{tabular}

Fonte: Academia de Polícia Militar (HAMADA, 2008). 
Observando atentamente o resultado das notas dos alunos e das matérias das turmas dessas três disciplinas, percebe-se claramente, que existem diferenças entre elas. Como verificado anteriormente, duas turmas de uma mesma disciplina ministrada por professores diferentes podem apresentar desempenhos diferenciados tanto no que tange à média das notas quanto no que se refere à aproximação ou ao distanciamento das notas de cada aluno em relação à média. Há turmas em que essa relação é mais homogênea e outras em que se identifica uma visível dispersão. A simples observação dessas discrepâncias não é suficiente para identificar os fatores que poderiam estar determinando essas diferenças. Foi isso que motivou a busca de um modelo de análise que pudesse esclarecer o que poderia estar impactando direta e linearmente o desempenho dos alunos do CTSP. Dito de outra forma, buscou-se um modelo que medisse a dependência funcional entre duas ou mais variáveis aleatórias. Foi assim que se chegou ao modelo estatístico denominado de Regressão Linear.

O referido modelo pode ser definido de duas maneiras: regressão linear simples e regressão linear múltipla. Esta, diferentemente da primeira, envolve três ou mais variáveis, algumas com a função de preditoras. Tem-se, no modelo, uma variável, chamada de dependente $(Y)$, que sofre influência de outras variáveis (independentes), de forma simultânea, dificultando ao analista identificar qual dessas variáveis tem mais ou menos peso na determinação do fenômeno.

Neste estudo, o fenômeno investigado envolveu a nota do aluno, a média da turma e a relação entre nota e média. A nota é a variável dependente (Y). A literatura educacional já indicou que vários fatores podem interferir no desempenho do aluno. Dos fatores identificados com esse poder, três dominam o conjunto das explicações: os relativos à família (herança, capital cultural, condições socioeconômicas), os concernentes à escola (condições dos estabelecimentos de estudo, liderança do gestor, qualificação docente e outros), os que tangem à comunidade (meio ambiente onde os alunos e professores advêm) e os que se ligam diretamente ao aluno (motivação, dedicação, projeto e expectativa para o futuro), e outros (BOURDIEU, 1998; BRESSOUX, 2003; GAUTHIER et al., 1998).

Muitos desses fatores têm sentido quando se investiga a educação formal, em especial, o ensino regular. Aliás, a maioria 
dos estudos enfatiza um ou outro, ou os combina para analisar os resultados educacionais do país, em termos de aprendizagem, de sucesso ou fracasso na escolarização.

Entretanto, para esta pesquisa, alguns desses fatores não teriam qualquer importância para determinar o desempenho do aluno aspirante à carreira de policial. Outros já estariam embutidos na própria seleção, homogeneizando, de certa forma, o conjunto de alunos que foram selecionados naquele ano. E há, também, um fator que é muito específico para o conjunto estudado, a saber: o fator motivação, que está ligado diretamente ao aluno.

No CTSP, espera-se que a motivação seja o fator mais determinante para o bom desempenho dos alunos, uma vez que, nesse caso específico, só a possibilidade de estar quase integrado em uma carreira profissional já é, em si, um fator que mobiliza os alunos a buscar bom desempenho (FERRETI, 1997; SOARES, 2006). Apenas lembrando, o curso do CTSP ainda faz parte do processo seletivo. Pode-se dizer que o aluno, quando chega ao curso, deu um passo para ingressar na carreira, ou seja, está com "um pé dentro da corporação". A aprovação no curso é condição sine qua non para que o segundo passo seja dado. Nesse sentido, é legítimo afirmar que a motivação tem o mesmo peso para todos os alunos. Entretanto, ainda que haja tantos fatores que os aproximem, é visível a dispersão que existe em termos de notas e de turma para turma. O que poderia explicar essas diferenças?

Voltando para a observação dos fatores escolares, ou seja, para aqueles que dizem respeito às condições oferecidas pelo CTSP, dificilmente haveria como propor ou seguir mudanças para fatores externos (família, escolarização formal, vivência comunitária etc.), indicando, dessa forma, como variável modelo, a variável indicadora "professor". Este, no conjunto do CTSP, é o único fator sujeito a uma grande variabilidade, pois todos os outros fatores internos (condições materiais do Centro) são iguais para todas as turmas, como já dito anteriormente. Já os professores não o são. Estes têm formações diferenciadas. Uns são da própria polícia, mas há um bom número deles que não é, logo não estão totalmente sujeitos à cultura interna da organização. Alguns têm mais tempo de sala de aula que outros. Parte deles desenvolve habilidades específicas para lidar com os alunos, e assim por diante. 
Nesse sentido, estimou-se que a análise de regressão linear múltipla seria o modelo mais adequado para estudar a influência das variáveis independentes sobre a dependente (nota e média da turma), porque permite eliminar a tendenciosidade derivada em relação a variáveis independentes que poderiam afetar substancialmente a variável dependente (Y), a nota do aluno.

Cabe esclarecer que, no modelo estatístico, foi utilizada a estratégia de incluir as variáveis, analisando a contribuição ou significância dos coeficientes de regressão de cada uma das variáveis independentes do modelo, eliminando a variável independente menos significativa. Portanto, foi incluída no modelo uma variável indicadora, tomando-se, em todos os casos, como categoria de referência, o professor cuja turma teve a menor nota média. Assim, o símbolo b0j refere-se a esse conjunto de variáveis indicadoras que identificam os professores das turmas de cada disciplina, onde se tomou o professor cujos alunos tiveram a menor nota média como referência. $\mathrm{O}$ quadro a seguir apresenta outras informações sobre as variáveis:

\begin{tabular}{|c|c|c|}
\hline VARIÁVEL & DESCRIÇÃO & VALORES \\
\hline Nota & $\begin{array}{l}\text { Nota do aluno } \\
\text { na disciplina }\end{array}$ & $\begin{array}{l}\text { Contínua, assumindo } \\
\text { valores de } \mathrm{O} \text { a } 10\end{array}$ \\
\hline Sexo & Sexo do aluno & $\begin{array}{l}0 \text { - feminino } \\
1 \text { - masculino }\end{array}$ \\
\hline Seleção & $\begin{array}{l}\text { Nota do aluno no } \\
\text { exame de seleção }\end{array}$ & 225,75 a 318,00 \\
\hline Situação & Tipo de matrícula & $\begin{array}{l}\text { O - mediante liminar judicial } \\
1 \text { - normal }\end{array}$ \\
\hline
\end{tabular}

Fonte: Academia de Polícia Militar (HAMADA, 2008).

Exceto a nota do aluno na seleção, as outras variáveis são qualitativas. Isso traz alguns problemas ao serem usadas nos modelos de regressão linear múltipla. Brower (2000), embora considere inadequado o uso dessas variáveis no modelo de regressão, sugere procedimentos que ajudariam a corrigi-las. Dentre esses procedimentos, está a transformação das variáveis 
qualitativas (categóricas) em variáveis indicadoras, também chamadas de variáveis mudas.

Entre as variáveis do Quadro 1, apenas a nota do aluno na seleção é medida em escala contínua. As variáveis sexo e situação associam apenas dois valores que, para facilitar a interpretação, são fixados em 0 e 1. Diante disso, o coeficiente da variável sexo nos modelos de regressão utilizados indica quantos pontos a mais (se positivo) ou menos (se negativo) o aluno do sexo masculino tem, depois de considerado o efeito das outras variáveis.

Para captar a influência dos diferentes professores na nota dos alunos, objetivo central deste trabalho, foi também necessário definir as variáveis indicadoras. Para isso, em todos os casos, tomou-se o professor cuja turma teve a menor média como referência, o que garantiu que a medida do efeito de cada professor fosse sempre positiva, facilitando, assim, o entendimento dos dados. A seguir, criaram-se tantas variações indicadoras quantas necessárias para representarem os outros professores da disciplina, além daquele tomado como referência. Um exemplo ilustra a situação. Se em uma disciplina há 5 turmas com 5 professores distintos e a turma do professor 3 é a de menor desempenho, as variáveis indicadoras referentes aos outros professores são definidas por:

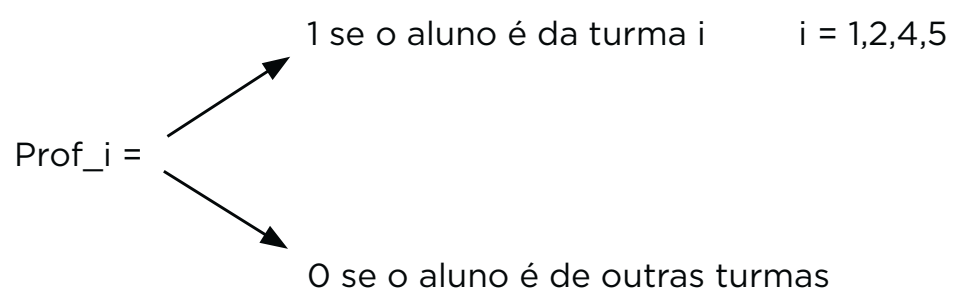

Ou seja, os coeficientes Prof1, Prof2, Prof4 e Prof5 indicam o número de pontos que cada um dos professores acrescenta a seus alunos depois de considerados os efeitos da nota do aluno no exame de seleção, seu sexo e sua situação.

Em suma, o uso dessa variável no modelo ajuda a reduzir a tendenciosidade para cima ou para baixo de outras variáveis explicativas que acabam justificando melhor o desempenho, dada a expectativa que se tem delas. As notas que os alunos tiram na seleção, se alta ou baixa, criam expectativas muito positivas de que eles se saíram melhor no curso. Conforme Muniz (1999), 
o sexo, ser homem ou mulher na carreira policial, tem criado expectativas de que homens se sairiam melhor, sobretudo nos conteúdos que reforçam o ethos da masculinidade da profissão (trabalho de homem, fortes, corajosos). A situação de como os alunos se encontram no curso, também. Por exemplo, o fato de haver alunos que entraram por força de uma liminar judicial, contrariando o resultado das provas da seleção pública, tem um peso que precisa ser medido, já que pode influenciar no resultado final.

Essas quatro variáveis em si, além da materialidade que três dela possuem, facilitando a observação, e incluindo agora o professor, são colineares e, por isso, estão altamente correlacionadas. A regressão múltipla é mais adequada do que a regressão simples, pois pode isolar a variável muda, estimando o seu peso na determinação da nota do aluno. A questão era saber qual seria a melhor aplicação da regressão múltipla para o presente estudo em especial.

Estudiosos da matéria indicam que existem três formas de aplicação:

a) a que chamam de padrão, que trabalha exclusivamente com valores numéricos;

b) a análise de variância (Anova), que equivale somente à regressão sobre variáveis mudas (indicadoras);

c) a análise de covariância (Anocova), que é a regressão sobre variáveis mudas e numéricas.

Em síntese, foi usada a Anova, por ser ela a que mais enquadrava no tipo de variável a ser testada no presente estudo.

Antes de entrar na análise de cada disciplina, é pertinente esclarecer os procedimentos adotados. Como eles são os mesmos para todas elas, decidiu-se por descrevê-los inicialmente, para, em seguida, apresentar o que ocorreu em cada disciplina, sem precisar ter de repeti-los em cada sequência.

Assim sendo, esclarece-se que, em primeiro lugar, dispõe-se a nota média por professor em um gráfico de forma a facilitar a visualização de como essa média se distribuía. Em seguida, apresentam-se as tabelas contendo o resultado do cálculo da regressão múltipla de cada disciplina. Foi por intermédio desse procedimento que se pôde observar que: a variável "professor" tinha um peso determinante no desempenho dos alunos, tornando o efeito de todas as outras variáveis sem 
significância estatística, e ainda a variância entre os professores, mostrando que alguns deles fazem muita diferença no desempenho dos alunos. E, por fim, apresenta-se a análise de variância de cada disciplina que fará parte do modelo de regressão múltipla, para mostrar se pelo menos uma das variáveis explicativas do modelo exerce efetivamente influência sobre a variável dependente: a nota do aluno.

Dito isso, passa-se à apresentação do que ocorreu em cada disciplina.

ANÁLISE DA DISCIPLINA DE ÉTICA PROFISSIONAL E CIDADANIA Considerando-se a nota média dos professores da disciplina de Ética Profissional e Cidadania, chegou-se à seguinte representação gráfica:

GRÁFICO 1 - Nota média por professor na disciplina de Ética Profissional e Cidadania do CTSP/2006

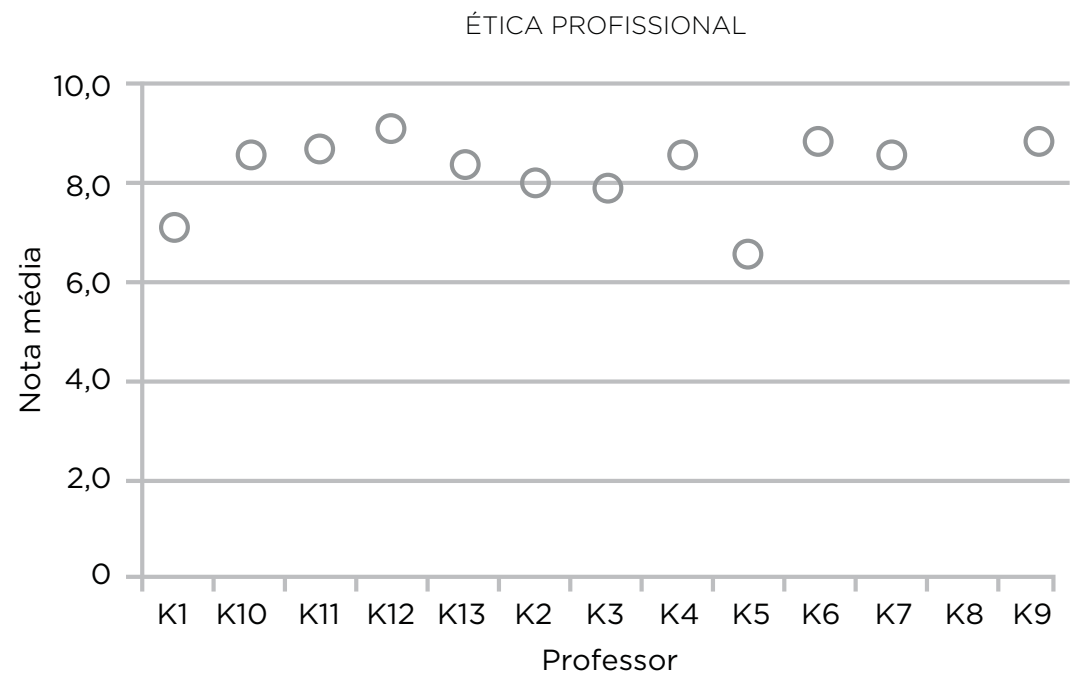

Fonte: Academia de Polícia Militar (HAMADA, 2008).

Conforme o gráfico acima, é visível a existência de uma grande dispersão entre a menor e a maior média dos professores. Como se pode perceber, dois deles (o Prof1 e o Prof.5) se aproximam bastante da nota média 6,0. Em contrapartida, as notas médias acima de 8,0 aparecem com uma frequência maior. Em suma, essa representação gráfica indica a existência de uma dispersão elevada entre as médias. 
Na aplicação do modelo de regressão linear múltipla, tem-se claramente a imagem de como se comporta o efeito conjunto das variáveis explicativas sobre a variável dependente (a nota do aluno) tal como pode se observar na Tabela 4:

TABELA 4 - Quadro de variáveis do modelo de regressão da disciplina de Ética Profissional e Cidadania

\begin{tabular}{|c|c|c|c|}
\hline \multirow{2}{*}{$\begin{array}{l}\text { VARIÁVEIS DO } \\
\text { MODELO }\end{array}$} & \multicolumn{2}{|c|}{ COEFICIENTES } & \multirow{2}{*}{ SIGNIFICÂNCIA } \\
\hline & BETA & ERRO PADRÃO & \\
\hline Constante & 7,112 & 0,477 & 0,000 \\
\hline Prof12 & 2,555 & 0,293 & 0,000 \\
\hline Prof9 & 2,532 & 0,242 & 0,000 \\
\hline Prof6 & 2,393 & 0,296 & 0,000 \\
\hline Prof4 & 2,279 & 0,244 & 0,000 \\
\hline Prof7 & 2,153 & 0,245 & 0,000 \\
\hline Prof11 & 2,131 & 0,296 & 0,000 \\
\hline Prof10 & 1,993 & 0,296 & 0,000 \\
\hline Prof13 & 1,826 & 0,297 & 0,000 \\
\hline Prof2 & 1,535 & 0,298 & 0,000 \\
\hline Prof3 & 1,316 & 0,243 & 0,000 \\
\hline Prof8 & 1,077 & 0,240 & 0,000 \\
\hline Prof1 & 0,489 & 0,299 & 0,102 \\
\hline Sexo & $-0,302$ & 0,280 & 0,282 \\
\hline Situação & $-0,091$ & 0,319 & 0,775 \\
\hline Nota de entrada & $-0,067$ & 0,040 & 0,097 \\
\hline
\end{tabular}

Fonte: Academia de Polícia Militar (HAMADA, 2008).

Como se pode ver, a influência de variáveis (sexo, situação e nota de entrada) que poderiam interferir nas diferenças foi retirada pelo próprio modelo de regressão. A significância estatística concentrou-se exclusivamente no efeito-professor. Com isso, pode-se afirmar que, na disciplina de Ética Profissional e Cidadania, os professores Prof12, Prof9, Prof6, Prof4, Prof7, Prof11, Prof10, Prof13, Prof2, Prof3 e Prof8, respectivamente, possibilitaram a seus alunos melhores notas que os professores Prof1 e Prof5. Entretanto, com exceção do Prof1, todos os outros acrescentam às notas de seus alunos valores maiores do que 1,0 ponto. $O$ grande destaque, contudo, é dado aos professores Prof12 e Prof9, cujas notas dos alunos foram 2,5 pontos maiores do que o do Prof5. Isso significa que ambos tiveram efeito bastante superior em relação aos seus alunos do que os demais professores do curso. 
Os resultados da Anova são corroborados pela análise de variância, conforme se verifica na Tabela 5:

TABELA 5 - Análise de variância da disciplina Ética Profissional e Cidadania

\begin{tabular}{|c|c|c|c|c|c|}
\hline & $\begin{array}{l}\text { SOMA DOS } \\
\text { QUADRADOS }\end{array}$ & $\begin{array}{l}\text { GRAUS DE } \\
\text { LIBERDADE }\end{array}$ & $\begin{array}{l}\text { MÉDIA DOS } \\
\text { QUADRADOS }\end{array}$ & $F$ & SIGNIFICÂNCIA \\
\hline Regressão & 774.424 & 15 & 51.628 & 14.290 & $0,000(a)$ \\
\hline Residual & $4.154,892$ & 1,15 & 3.613 & & \\
\hline Total & $4.929,315$ & 1,165 & & & \\
\hline
\end{tabular}

Fonte: Academia de Polícia Militar (HAMADA, 2008).

Com um F em 14,290, fica claro que pelo menos uma das variáveis explicativas tem efeito direto na nota do aluno e, como foi visto, essa variável foi o professor.

ANÁLISE DA DISCIPLINA DE ANÁLISE CRIMINAL

A representação gráfica da disciplina Análise Criminal traz algumas alterações quanto à variabilidade das médias, como se pode ver no gráfico a seguir:

GRÁFICO 2 - Nota média por professor na disciplina de Análise Criminal do CTSP/2006

ANÁLISE CRIMINAL

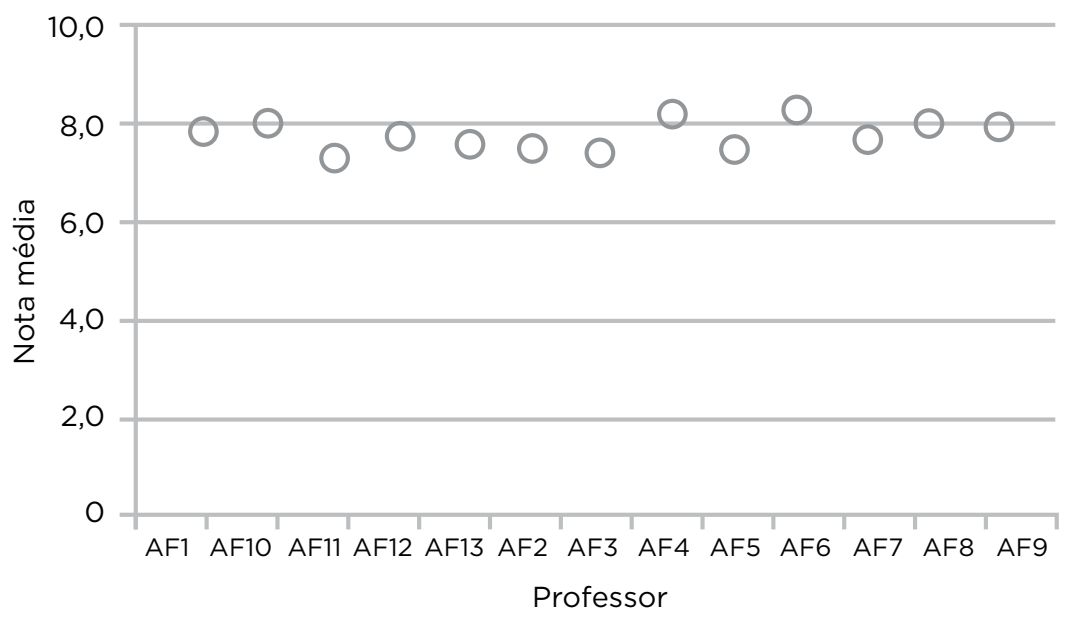

Fonte: Academia de Polícia Militar (HAMADA, 2008). 
Lendo o gráfico, atenciosamente, e observando-se a distância entre as médias máxima e mínima, nota-se uma pequena diferença entre as médias para cada professor na disciplina. No Gráfico 2, verifica-se que, diferentemente das disciplinas anteriores, os professores de Análise Criminal tiveram a nota média mínima e máxima com pouca variabilidade. Como se pode ver, os professores Prof4 e Prof6 obtiveram médias um pouco acima de 8,0 pontos e os professores Prof3, Prof5 e Prof11, com as menores médias, não se distanciaram muito, estando próximos a 7,0 pontos.

Apresentam-se também pequenas diferenças na Anova, como indica a Tabela 6:

TABELA 6 - Quadro de variáveis do modelo de regressão da disciplina de Análise Criminal

\begin{tabular}{l|c:c:c}
\hline \multirow{2}{*}{$\begin{array}{l}\text { VARIÁVEIS } \\
\text { DO MODELO }\end{array}$} & \multicolumn{2}{c}{ VARIÁVEIS DO MODELO } & SIGNIFICÂNCIA \\
\cline { 2 - 3 } Constante & BETA & ERRO PADRÃO & 0,000 \\
Prof4 & 7,686 & 0,652 & 0,006 \\
Prof6 & 0,890 & 0,322 & 0,045 \\
Prof8 & 0,782 & 0,390 & 0,025 \\
Prof10 & 0,721 & 0,322 & 0,081 \\
Prof1 & 0,685 & 0,392 & 0,110 \\
Prof9 & 0,636 & 0,398 & 0,113 \\
Prof7 & 0,631 & 0,399 & 0,174 \\
Prof12 & 0,538 & 0,395 & 0,348 \\
Prof13 & 0,370 & 0,394 & 0,315 \\
Prof2 & 0,325 & 0,323 & 0,549 \\
Prof5 & 0,238 & 0,398 & 0,904 \\
Prof3 & 0,039 & 0,322 & 0,968 \\
Sexo & 0,013 & 0,324 & 0,029 \\
Situação & $-0,823$ & 0,376 & 0,055 \\
Nota de entrada & $-0,099$ & 0,425 & 0,065 \\
\hline
\end{tabular}

Fonte: Academia de Polícia Militar (HAMADA, 2008).

Em comparação com a disciplina anterior, fica claro que na Análise Criminal os dados analisados pela Anova apresentam diferenças menos significativas estatisticamente entre as notas dos alunos dos diferentes professores. Assim, tomando-se como professor de referência o Prof11, apenas três professores tiveram coeficientes significativos, o que indica que houve certa homogeneidade na "eficácia” dos professores. 
Mesmo assim, verifica-se que o Prof4 foi o que apresentou maior diferença em relação ao professor de referência, acrescentando 0,89 ponto na nota dos seus alunos. Considerando que o próprio modelo de regressão retirou as outras variáveis que poderiam ter influência nas diferenças, destaca-se que o efeito-professor foi significativo estatisticamente apenas nos resultados dos professores Prof4, Prof6 e Prof8. Estes, e não os outros, possibilitaram melhores notas para os seus alunos.

Ainda que o modelo de regressão múltipla tenha indicado que as diferenças entre as médias são pequenas, a Tabela 7 mostra que nem por isso elas não devessem ser medidas.

TABELA 7 - Análise de variância da disciplina Análise Criminal

\begin{tabular}{l|c|c|c|c|c}
\hline & $\begin{array}{c}\text { SOMA DOS } \\
\text { QUADRADOS }\end{array}$ & $\begin{array}{c}\text { GRAUS DE } \\
\text { LIBERDADE }\end{array}$ & $\begin{array}{c}\text { MÉDIA DOS } \\
\text { QUADRADOS }\end{array}$ & F & SIGNIFICÂNCIA \\
\hline Regressão & 185.747 & 15 & 12.383 & 1.944 & O.016(a) \\
Residual & $7.333,235$ & 1,151 & 6.371 & & \\
Total & $7.518,982$ & 1,166 & & & \\
\hline
\end{tabular}

Fonte: Academia de Polícia Militar (HAMADA, 2008).

O resultado da análise de variância evidenciou que a variável professor era significativa para ser verificada sob o ponto de vista da investigação proposta na presente pesquisa.

\section{ANÁLISE DA DISCIPLINA DE PRONTO-SOCORRISMO}

A imagem que se tem da distribuição da nota média do Pronto-socorrismo reflete uma concentração dessas notas em torno dos valores médios, como se pode ver no Gráfico 3.

Do ponto vista gráfico, destacam-se nessa distribuição os Prof4 e Prof5 pela alta pontuação, contrastando com o Prof2, com baixa pontuação. Embora o restante permaneça na zona intermediária, isso não significa que não haja uma dispersão no conjunto analisado. 
GRÁFICO 3 - Nota média por professor na disciplina de Prontosocorrismo do CTSP/2006

DISCIPLINA: PRONTO-SOCORRISMO

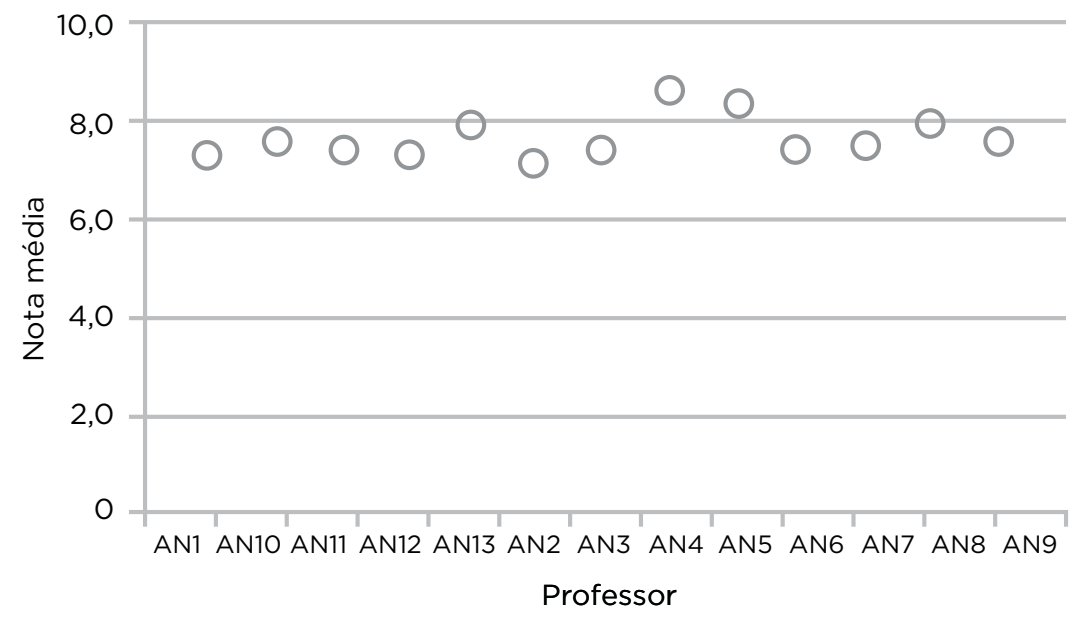

Fonte: Academia de Polícia Militar (HAMADA, 2008).

Ainda que não tão acentuadas, percebem-se pequenas diferenças entre os docentes no resultado do Anova, conforme a Tabela 8:

TABELA 8 - Quadro de variáveis do modelo de regressão da disciplina de Pronto-socorrismo

\begin{tabular}{l|c:c:c}
\hline \multirow{2}{*}{$\begin{array}{l}\text { VARIÁVEIS } \\
\text { DO MODELO }\end{array}$} & \multicolumn{2}{|c|}{ COEFICIENTES } & SIGNIFICÂNCIA \\
\hline Constante & BETA & ERRO PADRÃO & \\
Prof12 & 7.344 & 0,678 & 0,000 \\
Prof9 & 1.587 & 0,446 & 0,000 \\
Prof6 & 0,381 & 0,386 & 0,000 \\
Prof4 & 0,916 & 0,444 & 0,037 \\
Prof7 & 0,617 & 0,386 & 0,018 \\
Prof11 & 0,606 & 0,445 & 0,166 \\
Prof10 & 0,594 & 0,445 & 0,173 \\
Prof13 & 0,592 & 0,386 & 0,124 \\
Prof2 & 0,508 & 0,444 & 0,182 \\
Prof3 & 0,405 & 0,387 & 0,190 \\
Prof8 & 0,299 & 0,387 & 0,295 \\
Prof1 & 0,279 & 0,448 & 0,505 \\
Sexo & 0,786 & 0,388 & 0,472 \\
Situação & 0,435 & 0,364 & 0,031 \\
Nota de entrada & $-0,026$ & 0,409 & 0,288 \\
\hline
\end{tabular}

Fonte: Academia de Polícia Militar (HAMADA, 2008). 
Analisando-se as notas dos alunos da disciplina de Pronto-socorrismo pela Anova, verifica-se que houve diferenças entre os professores. Tomando-se o Prof2 como referência para a comparação por ter ele a menor média, pode-se observar que os professores Prof4, Prof5 são aqueles que apresentam diferenças estatisticamente significativas, ambos com valores $(\beta)$ acima de 1,0 ponto. Oprimeiro acrescentou 1,58 pontos nas notas finais dos alunos, e o segundo, 1,38 . Todos os outros professores, com exceção do Prof8 e do Prof13, que tiveram valores próximos a 1,0, não apresentaram diferenças significativas. Pelo modelo da análise de regressão, diferentemente do que acontece com as disciplinas anteriores, as variáveis que poderiam interferir nas diferenças dos professores foram afastadas, com exceção da variável sexo, que apresentou uma ligeira influência. Importante ressaltar que essa influência foi considerada pelo modelo de análise no cálculo do efeito de cada professor.

A análise de variância, como mostrada a seguir, permite afirmar que a diferença entre as médias foi significativa para as variáveis estudadas, e que pelo menos uma delas estaria interferindo na variável dependente. Como visto, trata-se do sexo e do efeito de dois professores, Prof4 e Prof5.

TABELA 9 - Análise de variância da disciplina Pronto-socorrismo

\begin{tabular}{|c|c|c|c|c|c|}
\hline & $\begin{array}{l}\text { SOMA DOS } \\
\text { QUADRADOS }\end{array}$ & $\begin{array}{l}\text { GRAUS DE } \\
\text { LIBERDADE }\end{array}$ & $\begin{array}{l}\text { MÉDIA DOS } \\
\text { QUADRADOS }\end{array}$ & $\mathrm{F}$ & SIGNIFICÂNCIA \\
\hline Regressão & 233.171 & 15 & 15.545 & 2.617 & $0.001(a)$ \\
\hline Residual & $6.836,739$ & 1,151 & 5.940 & & \\
\hline Total & $7.069,910$ & 1,166 & & & \\
\hline
\end{tabular}

Fonte: Academia de Polícia Militar (HAMADA, 2008).

O fato de a variável "sexo" ter significância no resultado do desempenho dos alunos, mais especificamente das alunas, reforça a ideia de que as atividades do cuidar na ação do policial conservam um viés feminino.

As outras quatro disciplinas que também demonstraram o efeito-professor foram Redação de Documentos $(0,12)$, Chefia e Liderança $(0,12)$, Polícia Comunitária e Informática Aplicada $(0,15)$. Essas não foram descritas porque apresentavam quase que as mesmas características das acima citadas, não acrescentando nenhum dado novo. Sendo assim, passa-se às considerações finais. 


\section{CONCLUSÃO}

Sob a ótica dos procedimentos associados ao aprendizado, procurou-se no presente estudo investigar o efeito-professor no Curso Técnico de Segurança Pública. Buscou-se controlar ao máximo os outros fatores envolvendo a família, o aluno, a sociedade e a própria escola, sendo o professor apenas um dos sujeitos dos fatores associados ao aprendizado, que Soares (2007) aponta como intra e extraescolares. Assim, tendo como suporte teórico os estudos sobre o efeito-professor, a pesquisa procurou alcançar o objetivo de verificar em que medida essa teoria permitia compreender os processos de formação dos policiais militares. As evidências encontradas demonstraram que o efeito-professor está presente no Curso Técnico em Segurança Pública, significando uma importante constatação científica, que servirá de base para avançar nos estudos no sentido de explicar por que determinados professores têm melhor desempenho do que outros no seu exercício da atividade docente.

Vale destacar também a influência que a variável sexo teve na disciplina Pronto-socorrismo. Essa disciplina, como se sabe, incorpora a dimensão do cuidar do outro, uma atividade identificada ao ethos feminino. $\mathrm{O}$ fato de ser mulher interferiu diferenciadamente nos resultados de desempenho. O que não aconteceu com as outras disciplinas, mesmo aquelas em que no imaginário de própria corporação se aproxima ao ethos masculino. Já no que se refere à variável condição de entrada do candidato, o estudo mostrou que mesmo para aqueles (minoria) que entraram por meio de liminares judiciais, essa variável não interferiu nos resultados da pesquisa.

Finalmente, ressalta-se que o presente estudo confirmou a ideia do quão importante é pensar a questão da atuação de docentes na formação dos agentes da Segurança Pública. Não há dúvida que selecionar os mais preparados para ocupar essa função é fundamental, mas nãoé o suficiente. A pesquisa mostrou que, no vasto conjunto de professores que estão ocupando essa função, apenas um grupo pequeno revelou estar fazendo diferença na formação desses profissionais. Isso indica que é preciso se realizarem mais pesquisas que avancem nesse processo, mostrando o que faz com que esses professores façam a diferença e como trabalhar para que o recrutamento de docentes com esse perfil seja um procedimento mais rotineiro nas Academias de Polícia. 


\section{REFERÊNCIAS}

ALVES, Maria Tereza G. Efeito-escola e fatores associados ao progresso acadêmico dos alunos entre o início da $5^{a}$ série e o fim da $6^{a}$ série do ensino fundamental: um estudo longitudinal em escolas públicas no município de Belo Horizonte. Tese (Doutorado em Educação) - Faculdade de Educação, Universidade Federal de Minas Gerais, Belo Horizonte, 2006.

ALVES, Maria Tereza G.; SOARES, José Francisco. As pesquisas sobre o efeito das escolas: contribuições metodológicas para a sociologia da educação. Sociedade e Estado, Brasília, v. 22, n. 2, maio/ago. 2007.

BARBOSA, Maria Eugénia F.; FERNANDES, Cristiano. A escola brasileira faz diferença? Uma investigação dos efeitos da escola na proficiência em matemática dos alunos da $4^{\mathrm{a}}$ série. In: FRANCO, Creso (Org.). Promoção, ciclos e avaliação educacional. Curitiba: ArtMed, 2001.

BASTOS, João Luiz D.; DUQUIA, Rodrigo P. Medidas de dispersão: os valores estão próximos entre si ou variam muito? Scientia Médica, Porto Alegre, v. 17, n. 1, p. 40-44, 2007.

BOURDIEU, Pierre. Futuro de classe e causalidade do provável. In: NOGUEIRA, Maria Alice; CATANI, Afrânio (Org.). Escritos de Educação. Petrópolis: Vozes, 1998. p. 81-126.

BRESSOUX, Pascal. As pesquisas sobre efeito-escola e o efeito-professor. Tradução de Isabel Cristina Rabelo Gomes. Educação em Revista, Belo Horizonte, n. 38, dez. 2003.

BROOKE, Nigel; SOARES, José Francisco (Org.). Pesquisa em eficácia escolar: origens e trajetórias. Belo Horizonte: UFMG, 2008.

BROWER. K. M. The ANOVA Procedure using MINITAB. Scientific Computing and Instrumentation, p. 14, 2000.

COLEMAN, James S. et al. Equality of Educational Opportunity. In: BROOKE, Nigel; SOARES, José Francisco (Org.). Pesquisa em eficácia escolar: origens e trajetórias. Belo Horizonte: UFMG, 2008. p. 26-32.

CUNHA, Maria Isabel. A construção do conhecimento na prática pedagógica do professor do ensino superior. Araraquara: JM, 2003.

FERRETI, Celso João. Formação profissional e reforma de ensino técnico no Brasil: anos 90. Educação \& Sociedade, Campinas, n. 59, p. 225-269, 1997.

GAUTHIER, Clermont et al. Por uma teoria da pedagogia. Tradução de Francisco Pereira de Lima. Porto Alegre: Unijuí, 1998.

HAMADA, Hélio Hiroshi. Ensino profissional na Polícia Militar de Minas Gerais: análise do efeito-professor no curso técnico em segurança pública. 2008. 145 f. Dissertação (Mestrado em Educação) - Faculdade de Educação, Universidade Federal de Minas Gerais, Belo Horizonte, 2008.

KANT DE LIMA, Roberto. Direitos civis, estado de direito e "cultura policial": a formação policial em questão. Revista Brasileira de Ciências Criminais, São Paulo, v. 41, jan./mar. 2003. 
MELLO, Guiomar N. de. Magistério do primeiro grau: da competência técnica ao compromisso político. 3. ed. São Paulo: Autores Associados e Cortez, 1983.

MINAS GERAIS. Polícia Militar. Revista comemorativa do $15^{\circ}$ aniversário do Centro de Recrutamento e Seleção, Belo Horizonte, 2008.

MUNIZ, Jaqueline de O. Ser policial é, sobretudo, uma razão de ser: cultura e cotidiano da Polícia Militar do Rio de Janeiro. Tese (Doutorado) - Instituto Universitário de Pesquisas do Rio de Janeiro, Rio de Janeiro, 1999.

PONCIONI, Paula. O modelo policial profissional e a formação profissional do futuro policial nas academias de polícia do estado do Rio de Janeiro. Sociedade e Estado, Brasília, v. 20, n. 3, p. 585-610, 2005.

ROSEMBERG, Lia. Educação e desigualdade social, São Paulo: Loyola, 1984.

SAPORI, Luis Flávio. Segurança pública no Brasil: desafios e perspectivas. Rio de Janeiro: Editora da FGV, 2007.

SOARES, José Francisco. Melhoria do desempenho cognitivo dos alunos no ensino fundamental. Cadernos de Pesquisa, São Paulo, v. 37, n. 130, p. 135-160, jan./abr. 2007.

SOARES, José Francisco; ANDRADE, Renato J. Nível sócio-econômico, qualidade e equidade das escolas de Belo Horizonte. Ensaio: Avaliação e Políticas Públicas em Educação. Rio de Janeiro, v. 14, n. 50, p. 107-126, jan./mar. 2006.

SOARES, José Francisco; COLLARES, Ana Cristina M. Recursos familiares e desempenho cognitivo dos alunos do ensino básico brasileiro. Dados, v. 49, p. 615-650, 2006.

SOARES, José Francisco; SIQUEIRA, Arminda Lucia. Introdução à estatística médica. 1. ed. Belo Horizonte: UFMG/ Departamento de Estatística, 1999.

SOARES, Luiz Eduardo. Segurança pública: presente e futuro. Estudos Avançados, v. 20, n. 56, p. 91-106, 2006.

\section{LUIZ ALBERTO OLIVEIRA GONÇALVES}

Doutor em Sociologia pela École des Hautes Études en

Sciences Sociales/Paris. Pós-doutorado na Universidade de

São Paulo. Professor associado de Metodologia de Pesquisa

no Departamento de Ciências Aplicadas à Educação da

Faculdade de Educação da Universidade Federal de Minas

Gerais (FaE/UFMG). Pesquisador do Grupo de Avaliação

e Medidas Educacionais (GAME) da FaE/UFMG

luiz.goncalves@pq.cnpq.br; laog@fae.ufmg.br 
JOSÉ FRANCISCO SOARES

Doutor em Estatística pela University of Wiscosin e pósdoutor pela University de Michigan - Ann Arbor. Professor titular aposentado do Departamento de Ciências Aplicadas à Educação da Faculdade de Educação da Universidade Federal de Minas Gerais (FaE/UFMG). Coordenador do Grupo de Avaliação e Medidas Educacionais (GAME) da FaE/UFMG francisco.soares.ufmg@gmail.com

\section{HÉLIO HIROSHI HAMADA}

Doutorando em Educação pela Universidade Federal de Minas Gerais (UFMG). Docente e orientador de pesquisa na Academia de Polícia Militar do Estado de Minas Gerais heliohamada@oi.com.br 